\title{
Challenges of Digital Transformation: The case of the Non-Profit Sector
}

\author{
Shafiee Nahrkhalaji, S.; Shafiee, S.; Shafiee, M. ; Hvam, L.
}

Published in:

Proceedings of 2018 IEEE International Conference on Industrial Engineering and Engineering Management (IEEM)

Link to article, DOI:

10.1109/IEEM.2018.8607762

Publication date:

2019

Document Version

Peer reviewed version

Link back to DTU Orbit

Citation (APA):

Shafiee Nahrkhalaji, S., Shafiee, S., Shafiee, M., \& Hvam, L. (2019). Challenges of Digital Transformation: The case of the Non-Profit Sector. In Proceedings of 2018 IEEE International Conference on Industrial Engineering and Engineering Management (IEEM) (pp. 1245-1249). IEEE. https://doi.org/10.1109/IEEM.2018.8607762

\section{General rights}

Copyright and moral rights for the publications made accessible in the public portal are retained by the authors and/or other copyright owners and it is a condition of accessing publications that users recognise and abide by the legal requirements associated with these rights.

- Users may download and print one copy of any publication from the public portal for the purpose of private study or research.

- You may not further distribute the material or use it for any profit-making activity or commercial gain

- You may freely distribute the URL identifying the publication in the public portal 


\title{
Challenges of Digital Transformation: The case of the Non-Profit Sector
}

\author{
S. Shafiee Nahrkhalaji ${ }^{1}$, S. Shafiee ${ }^{2}$, M. Shafiee ${ }^{3}$, L. Hvam $^{4}$ \\ ${ }^{1}$ DTU Business, Technical University of Denmark, Lyngby, Denmark \\ ${ }^{2}$ Department of Mechanical Engineering, Technical University of Denmark, Lyngby, Denmark \\ ${ }^{3}$ E-Learning Center, Shahid Beheshti University, Tehran, Iran \\ ${ }^{4}$ Department of Management Engineering, Technical University of Denmark, Lyngby, Denmark \\ (Shafieesaeedeh2010@gmail.com, sashaf@dtu.dk, mitrash76@gmail.com, lahv@dtu.dk)
}

\begin{abstract}
Nonprofit organizations (NPOs) are critical to the quality of life in many communities not only due to the valuable services and social impact they create, but also because of the positive economic impact within local communities. However, NPOs, just as for-profits, need to innovate in response to changing customer demands and lifestyles and to capitalize on opportunities offered by technology and changing marketplaces, structures and dynamics. Digitalization is essential to fuel NPO's innovation in order to be a differentiator in the highly competitive environment. In this paper, we first develop a review to identify the challenges of digital transformation and then we examine some of the challenges that the nonprofit sector faces in undertaking digital transformation initiatives.

Keywords - Digitalization, digital transformation, nonprofit organizations
\end{abstract}

\section{INTRODUCTION}

Digital transformation as a radical rethinking of using technology to change customer experience, operational processes, and business models [1]. To fundamentally impact different aspects of business and society, the new technological and societal trends is unavoidable [2]. The World Economic Forum estimates that digital transformation across industries over the next 10 years will create upwards of $\$ 100$ trillion in newly created values, new economic opportunity, and reduction of negative market impact [3]. Non-profit sector is not an exception. In fact, digital transformation is a strategic, organization-wide approach that brings together people, process, and technology to create social impact through free-flowing insight that enables innovation [4]. Therefore, to compete and survive, NPOs also must include appropriate digital transformation as a core strategy. However, firms in various sectors face new challenges when taking different initiatives into digital transformation.

The challenges are not necessarily operational or technological, but the cultural change required to derive value from digitalization is also critical. Researchers have shown a high interest in the drivers, challenges and consequences of digital transformation in the organizations due to the novelty and complexity of the issue. However, the focus of most studies is on the technological aspects of digital transformation. This research-in-progress article considers different types of challenges facing managers undertaking digital transformation initiatives. Further, based on a survey conducted in the non-profit sector, we examined the key challenges and internal and external actors who influence NPOs when it comes to changes generated by digital technologies.

\section{LITERATURE STUDY}

\section{A. Digital transformation}

Digital Transformation can be interpreted differently in different companies and sectors because they have different levels of digital maturity and different values, stakeholders and visions. However, normally the theme is applying technology to create better operations and strategic business differentiation [5] or to radically improve performance or reach of enterprises [1]. Therefore, digital transformation can be defined as a radical rethinking of using technology to change strategy, revenue streams, operations and business models leading to significant impact for customers, partners, and employees [6]. Digital transformation, apart from the type of technology, involves changing three key areas of an organization: customer experience, operational processes and business models. Defining it as a specific project with a beginning phase, an implementation phase, and a maintenance phase can be very simplistic. It is a longterm process of change [1].

\section{B. Challenges of digital transformation}

Companies in any sector face a range of challenges in deploying and managing digital transformation. The challenges can be organizational, strategic, cultural or managerial.

The emergence of technical platforms and big data analytics bring profound changes in organizational structures, firms' strategy and management processes and require new frameworks to analyze and understand complex patterns of competition and corporation [7]. Intermediating the role of technical platforms between a set of complementary suppliers and a set of customers and operations to translate the accessed, structured, analyzed data into value creating services. Meanwhile, related privacy issues require new internal organizational structures and innovative types of management [8].

Digital transformation is associated with challenges to develop viable business models and constantly experiment and iterate the new business model ideas. The managerial issue is which parts of the current business model can be stabilized, if any, and which parts needed to be kept agile and adaptable [1]. Moreover, companies must find a scalable way to implement their digital transformation strategies and ensure that they can 
transform their innovation into new revenue streams as part of the business model.

The business model scalability enables the company to find a way to go to market, create value for new stakeholders and transform the value into real cash flows based upon a new revenue model [8].

Companies need to shift from product to servicebased business models which means that uncertainties will emerge, and complexities need to be acknowledged. Furthermore, the value of the new digitally-based service for a user may be more or less difficult to perceive and evaluate when going through a digital transformation [8, 9].

Digitalization involve many knowledge areas, new digital technologies and platforms, and actors from several industries in new partnerships. Collaborations across sectors and industries that occur in digital transformation processes enable firms to accelerate innovation and create more competitive market positions [8]. However, these partnerships bring conflicts between different actors with different business models. Some old partners may even change to potential competitors [9].

The growing digital ecosystems are more usercentric; thus, user experience and customer value receive special attention, which challenges sales-based business models. Changes in connectivity, advances in analytics and artificial intelligence, and the growing profusion of smart devices requires companies to have new digital support systems and platforms in aggregated marketplaces to analyze digital customer journeys and behaviors [8]. However, this can jeopardize customization of services as too much emphasis on patterns and customer categories and stereotypes leads to depersonalization [10].

Leadership capabilities are essential to achieving true digital transformation and to turn digital investment into digital advantage. Hiring new IT staff and new chief digital officer is not a guarantee to success. Digital transformation is a big challenge. It cannot happen without the support from top managers and the CEO who can foster a corporate culture that effectively drives digital transformation. The responsibility of creating a transformative vision of how the firm will be different in the digital world, and then engaging employees to make the vision a reality rest with the CEO [11].

Digital transformation is not only deploying a sophisticated technology or an IT exercise but also a people exercise [12]. Findings from the IT Sloan Management Review and Deloitte studies on digitalization reveal that that the biggest challenge organizations are facing in accelerating transformation is not necessarily around the new technology itself, but the cultural change required to derive value from it. Therefore, this highlights the role of humans, organizational culture and the need for formal strategic planning in successful digital transformation [13]. Further, another researcher [14] contends that a close alignment between 'fundamental changes in corporate culture' with the adoption of a 'constellation of technologies' is essential.

\section{Non-profit organizations}

NPOs are critical to the quality of life in many communities not only because of the valuable services and social impact they provide to local citizens, but also because of the positive economic impact within the local communities. They are a steady source of employment and provide employees with a source of income. Therefore, just like for-profits, they can promote economic growth. [15]. For-profits like any other business, consume third-party goods and services in their day-to-day operations. This generates revenue for the companies that manufacture and distribute these goods and services, thereby providing added economic stimulation [4]. Hence, NOP's critical role in building civil society and strengthening the nexus between social capital and economic development makes them vital to economic well-being of any country.

NPOs are crucial to social accountability. They can improve governance of public institutions and businesses by focusing on transparency. NPOs are also seen as a source of innovation in solving social problems with much better performance than government, because of their smaller scale and greater proximity to communities that make them creative agents in finding solutions [15].

Non-profits do not sell anything per say, but they are trying to sell their mission, their programs, and their services to clients, donors, volunteers, and staff members. A non-profit should differentiate their services from the rest of the non-profit sector-with a competitive advantage [4].

In addition to these characteristics, there are other significant and consistent differences between nonprofits and for-profits. In general, they are different in their missions, target audiences, and problem-solving strategies. However, more specifically, NPOs are different regarding the primacy of nonfinancial outcomes, limited availability of resources, their funding operations, their organizational culture, lower compensation of staff and managers, their leadership style and the absence of direct incentives for increasing productivity [16].

NPOs are facing environmental pressures from increasing numbers of agencies seeking support, raising their funds, new trends in donation, and the presence of for-profit organizations in human services [17]. Success and survival demand that nonprofits operate more like for-profit organizations, seeking competitive advantage through innovation. Customer demands, marketplaces, structures and dynamics change, and technology offers new opportunities to capitalize on. In response to all these changes, NPOs need to innovate that can mean many different things. It can mean new ways of managing organizations, new ways of rewarding people, new opportunities of fundraising, and new communication styles. It involves creating, developing and implementing practical ideas that achieve a public benefit. These ideas should be at least in part new (rather than improvements); they have to be taken up and used (rather than simply remaining ideas); and they have to be useful. to keep in touch with the problem-relevant environment and can use 
this information for refining and revising the chosen solution path(s) [18].

\section{DIGITAL TRANSFORMATION CHALLENGES IN NONPROFT ORGANIZATIONS}

Digitalization for NPOS means greater efficiency as it makes work straightforward, communication simpler, and collaboration seamless. Digitalization enables NPOs to reduce labor costs by automating manual tasks, personalize donation process, increase transparency and trust digital, raise friends rather than funds, virtualize paperless marketing and decentralize their services [19]

In addition to opportunities, digital transformation brings challenges to these organizations. As any other industry and sector, digitalization is not the only solution to sustainable development of NPOs despite the extraordinary power. Adopting a well thought out digital strategy that connects people, processes, and technology can accelerate the social impact and realize your mission [4].

New customer interaction processes created by digital transformation brings changes in business models. They should be relationship-oriented rather than transactionoriented that requires the development of new sets of capabilities such as marketing and sales incentives [8]. The digital journey and behavior of the customers including beneficiaries, donors, volunteers, and members and new digitalized interactions with them should be analyzed. This requires the implementation of a wide range of new digital marketing technologies, systems, and solutions. These new marketing technologies can shape newly emerging marketing platforms, thus, connecting the digitalizing NPO with its digitalizing customers. The challenges of this digitalization for marketing operations in NPOs can be 'the speed and pace of the responses to, and reactions from, customer actions'. Continuous interaction processes and deep and on - going insight into customer journeys can significantly affect the marketing planning processes. This, in turn, creates challenges for the general strategies of NPOs $[1,8,9]$.

In sum, digital transformation of NPOs increases customer complexity and changes interaction with customers. The process is also associated with changes in the value offering as well. Moreover, new partnerships need to be established and new infrastructures should be created. Last but not least, dimensions of business models need to be developed and implemented when it concerns the financial and economic, which includes revenue as well.

\section{RESEARCH DESIGN}

With specific features of NPOs and generic challenges of digital transformation in mind, this paper delves deep into the challenges that NPOs encounter as they navigate their own unique digital transformation journeys and the influence of the key stakeholders on their digital transformation.

We carried out a survey to ask the key decision makers involved in digitalization projects and initiatives in NPOs to rank ten key challenges their organizations may encounter in undertaking digital transformation initiatives. The rest of the survey contained questions about the key stakeholders who influence on NPOs' efforts to develop digital processes. The respondents had to provide a value between 0 and 10 according to the influence of each stakeholder. The questionnaire had a reliability (Cronbachs alpha) of 0.83 .

We sent surveys out by email during the winter of 2017-2018 to 89 potential respondents in 30 small and midsized non-profit organizations in middle-east that have been active in a wide range of social issues such as children and women's rights, environment conservation, animal welfare and health research. We received 68 (22 board members; 27 CEOs and 19 founders) completed surveys from the organizations.

\section{RESULTS AND DISCUSSIONS}

We posed questions regarding the main challenges of digital transformation that are discussed in the literature. These challenges include availability of resources, development of new capabilities and skills, corporate culture, finding the right leadership, engagement of employees, market uncertainties,

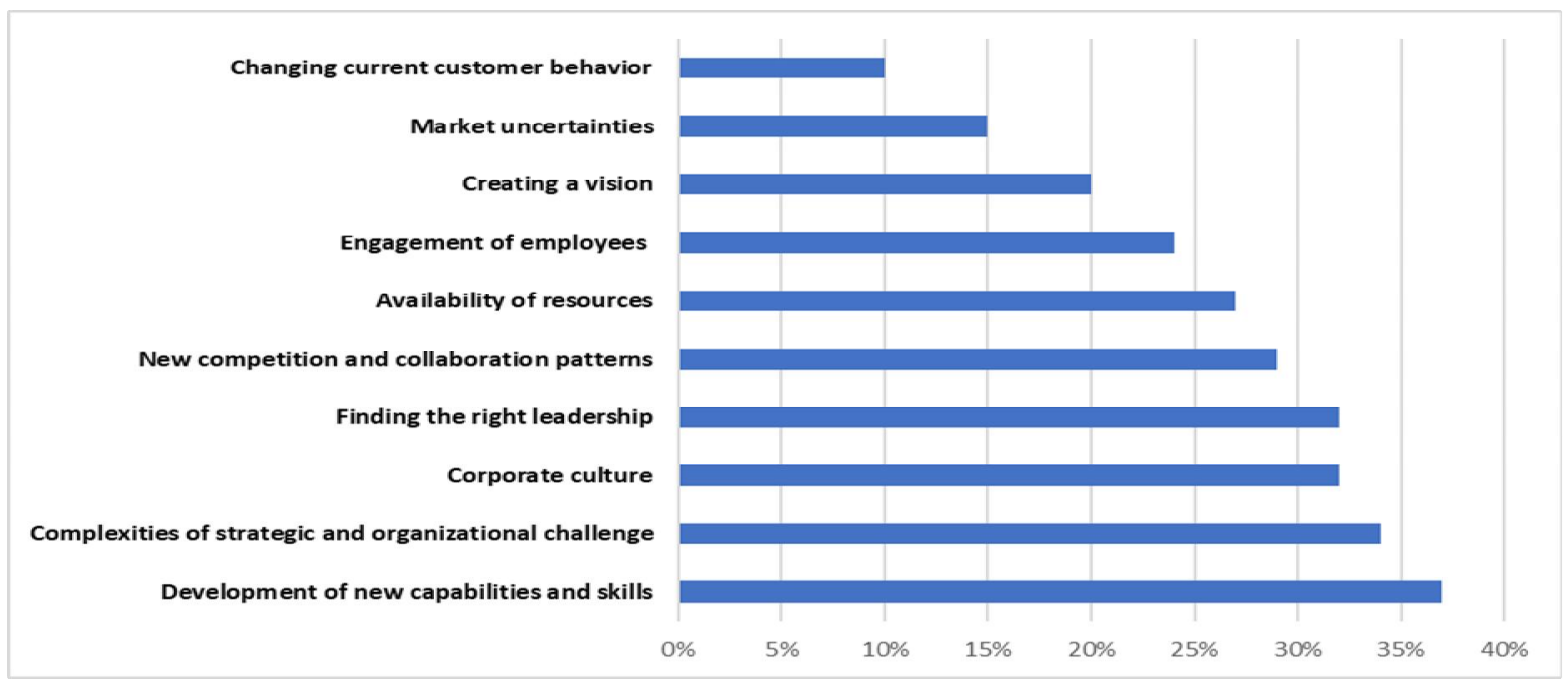

Fig. 1 Key challenges of digital transformation in NPOs 
complexities of strategic and organizational challenges, new competition and collaboration patterns, changing current customer behavior and creating a vision. The results are illustrated as a graph in Figure 1.

Development of new capabilities and skills is the most significant challenge in digital transformation $(37 \%$ of respondents). This seems to indicate that in addition to technological resources that are required to ensure a digital transformation, there is also a significant need for people with skills with different digital technologies. The competition for capabilities and technological experience with social and mobile technology, artificial intelligence, big data analytics, internet of things, and more is expected to increase.

The other big challenge is to grasp the complexities of the strategic and organizational challenges that NPOs face when taking the next steps into digitalization. The findings also reveal that digital transformation entails not only applying new technology but also changing the organization's structures, processes, culture and mindset so that it is able to more nimbly adopt to changes in the business environment. The respondents have a significant awareness of the effect of expanding partnerships and changes in customer segmentation, often resulting in increased overlapping of networks and, consequently, new patterns of cooperation and competition. They also know that right leadership weave a new cultural signature within the organization to envision and drive transformation. Apparently, the customers in this sector mainly beneficiaries, donors, volunteers, members show a high willingness to digital solutions.

Without a strong willingness and commitment to spend the time and effort on exploring digital technology's business implications, there is a risk that technologies are being deployed in ways that do not create strategic value [20].

The findings of the survey suggest that a key aspect of committing to digitalization in NPOs might stem from the ways in which external and internal parties influence the shaping of a firm's strategic agenda. Therefore, we also explored what kind of internal and external influencers affect NPOs' digital transformation efforts in middle-east. We asked our respondents about the relative importance of various actors.

Table 1 displays that the most important influences on NPOs' digital transformation efforts come from the board of directors, followed by $\mathrm{CEO}$ and middle management. This highlights the importance of corporate governance in setting not only the strategic agenda in general, but also in articulating the role of digitalization in the strategic development of the organization. Clearly, the influence from the top including digital leadership of the CEO can explain why the right leadership that can change the vision and corporate culture is one of the key challenges.
TABLE I

Digitalization Influencers in NPOs' Digital Transformation Efforts

\begin{tabular}{|l|l|l|l|l|l|}
\hline \multicolumn{1}{|c|}{ Digitalization Influencers in NPOs' Digital Transformation Efforts } \\
\hline $\begin{array}{l}\text { Board of Directors and } \\
\text { Trustees }\end{array}$ & 5.6 & 13.5 & 22.1 & 39.4 & 19.4 \\
\hline CEO & 11.3 & 13.1 & 21 & 37 & 17.6 \\
\hline Middle management & 10 & 9.8 & 31.2 & 33.9 & 15.1 \\
\hline Donors and volunteers & 10.4 & 8.6 & 33.2 & 32.8 & 15 \\
\hline Media and public debate & 9.3 & 15.6 & 26.8 & 33.7 & 14.6 \\
\hline $\begin{array}{l}\text { Non-management } \\
\text { employees }\end{array}$ & 10 & 29.5 & 28.1 & 21.6 & 10.8 \\
\hline Existing competitors & 25.6 & 32.2 & 15.7 & 17.1 & 9.4 \\
\hline Consultants & 36.9 & 30 & 11.4 & 13.4 & 8.3 \\
\hline Beneficiaries & 35.2 & 12 & 10.4 & 17.5 & 7.4 \\
\hline Governmental institutions & 37 & 28.9 & 22.3 & 7.9 & 3.9 \\
\hline
\end{tabular}

NI: Not Important; SI: Slightly Important; MI: Moderately Important; VI: Very Important; EI: Extremely Important

\section{CONCLUSION}

There is an increasing call for digitalization in NPOs. However, damage to corporate image, organizational inertia, lack of resources and tech expertise and fear of change are the main restraining forces which mostly come from board members and top management.

This research-in-progress paper considers challenges for managers pursuing digital transformation in NPOs. Although most of studies focus on technology as part of a digital transformation strategy, the organizations aspiring to digital transformation maturity need to reinvent their organizational business models, improve decisionmaking, find the right leadership, deal with complexities and uncertainties that new competition and collaboration patterns impose and improve customer engagement. In comparison, the main challenges that for-profits face in taking digital transformation initiatives mostly concern coping with user-centric systems, managing big data, shifting from product to service-based business models and translating digital solutions into scalable business models to target larger market [20].

Our survey also shows that different internal and external stakeholders have different level of influence on digital transformation efforts in NPOs. CEO, the top management team and middle managers are the most influential actors who can push through the digital transformation.

To begin a transformation journey, hence, managers in NPOs need to move beyond focusing on technology and devote time and effort to develop new leadership skills and comprehensive digital technology capabilities in the organization. Organizational considerations such as strategy formulation, cultural change, and development of technological and leadership capabilities are necessary in this journey. Digital transformation can both solve problems and create new challenges and the organizations need to be aware of them. NPOs can create stronger longterm social impact through achieving successful digitalization leading to adopting more innovative solutions and better customer experience. 
The final step which is the ongoing process in our research will be to create a conceptual framework to help leaders in NPOs to understand and cope with the challenges and opportunities that digital transformation can bring to their enterprises.

\section{REFERENCES}

[1] G. Westerman, D. Bonnet, and A. McAfee, "The nine elements of digital transformation," MIT Sloan Management Review, 2014. [Online], Available: http://sloanreview.mit.edu/article/the-nine- elements-ofdigital-transformation/. [Accessed Apr. 18, 2018].

[2] G. Gruman, "What digital transformation really means, " InfoWorld., 2016. [Online], Available: http://www. infoworld.com. [Accessed Feb.20, 2018].

[3] World Economic Forum, in collaboration with Accenture, "Digital Transformation of Industries, Demystifying Digital and Securing \$100 Trillion for Society and Industry by 2025," January 2016.

[4] J Spelhaug J. and L Woodman,"The New Imperative of Nonprofit Digital Transformation. A strategic approach for achieving exponential impact through people, process, and technology," 2017. [Online], Available: https://cdn2. hubspot.net/hubfs/575821/Nonprofit\%20Digital\%20Transf ormation\%20Whitepaper_9_23_17.pdf. [Accessed June 1. , 2018].

[5] P. Andersson, S. Movin, M. Mähring, R. Teigland, and K. Wennberg, Eds., Managing Digital Transformation. Stockholm School of Economics Institute for Research, 2018.

[6] C. Boulton, "What is digital transformation? A necessary disruption," 2017. [Online], Available: https://www.cio. com/article/3211428/digital- transformation/what-is-digitaltransformation-a-necessary-disruption.html\#tk.cio_rs. [Accessed Apr. 19, 2018].

[7] Yoo Y., Henfridsson O. and Lyytinen, K., "The new organizing logic of digital innovation: An agenda for information systems research," Information Systems Research, vol. 21, no.4, 724-735, 2010.

[8] P. Andersson and C. Rosenqvist, "Strategic Challenges of Digital Innovation and Transformation, "in Managing Digital Transformation, P. Andersson, S. Movin, M. Mähring, R. Teigland, and K. Wennberg, Eds. Stockholm School of Economics Institute for Research, 2018, pp. 1741.

[9] Andersson P., and Mattsson LG., "Digital Transformation Supporting Public Service Innovation: Business Model Challenges and Sustainable Development Opportunities, "in Managing Digital Transformation, P. Andersson, S. Movin, M. Mähring, R. Teigland, and K. Wennberg, Eds. Stockholm School of Economics Institute for Research, 2018, pp. 217-243.

[10] H. Tiersky, "5 top challenges to digital transformation in the enterprise, "Retrieved February 28, 2018, from https://www.cio.com/article/3179607/e-commerce/5-topchallenges-to-digital- transformation-in-the-enterprise.html, 2017.

[11] World Economic Forum, Unlocking Digital Value to Society: A New Framework for Growth. In Collaboration With Accenture. White Paper, January 2017.

[12] Microsoft UK Enterprise Team, Creating a culture of digital transformation. Report, Dember, 2017.
[13] G.C. Kane, D. Palmer, A. N. Phillips, D. Kiron, and N. Buckley (2015), "Technology, drives digital transformation - becoming a digitally mature enterprise“ MIT Sloan Management Review, 2015. [Online], Available: https://sloanreview.mit.edu/projects/strategy-drives-digitaltransformation/ [Accessed Apr. 16, 2018].

[14] J. McKendrick, "The 5 traits of digitally advanced companies," $2017 . \quad$ [Online], Available: https://www.forbes.com [Accessed Apr. 15, 2018].

[15] M.B. Veenswijk, Ed., Organizing innovation. New approaches to cultural change and intervention in public sector organizations. Amsterdam, Oxford, Fairfax. 2015.

[16] J. Phills, Integrating mission and strategy for nonprofit organizations. New York: Oxford University Press, 2005.

[17] C. Chetkovich and P. Frumkin, "Balancing margin and mission nonprofit competition in charitable versus fee based programs," Administration and Society, vol.35, no.5, pp.564 - 96, 2003.

[18] R. Dart, Being, "Business-like in a Nonprofit Organization: A Grounded and Inductive Typology," Nonprofit and Voluntary Sector Quarterly, vol. 33, pp. 290-310, 2004.

[19] L. Herbert, Digital Transformation: Build Your Organization's Future for the Innovation Age. London: Bloomsbury Publishing, 2017.

[20] G. Westerman, D. Bonnet, and A. McAfee, Leading digital: turning technology into business transformation, Harvard Business Review Press, 2014. 